Supporting information:

\title{
Cross dipole stacking in the crystal of distyrylbenzene derivative: the approach towards high solid-state luminescence efficiency
}

\author{
Zengqi Xie, ${ }^{\dagger}$ Bing Yang, ${ }^{\dagger}$ Feng $\mathrm{Li}^{\dagger}{ }^{\dagger}$ Gang Cheng, ${ }^{\dagger}{ }^{\ddagger}$ Linlin Liu, ${ }^{\dagger}$ Guangdi \\ $\mathrm{Yang}^{\dagger}{ }^{\dagger} \mathrm{Hai} \mathrm{Xu},{ }^{\dagger}$ Ling $\mathrm{Ye}^{\dagger}{ }^{\dagger}$ Muddasir $\mathrm{Hanif}^{\dagger}$, Shiyong Liu, ${ }^{\ddagger}$ Dongge $\mathrm{Ma}^{\S}$ \\ and Yuguang $\mathrm{Ma}^{*, \dagger}$
}

${ }^{\dagger}$ Key Lab for Supramolecular Structure and Materials of Ministry of Education, Jilin University, Changchun 130012, P. R. China

ॠState Key Laboratory of Integrated Optoelectronics, Jilin University, Changchun130012, P. R. China

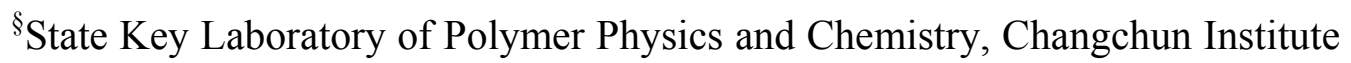
of Applied Chemistry, Chinese Academy of Sciences, Changchun 130022, P. R. China

\section{General experiments}

The ${ }^{1} \mathrm{H}$ NMR and ${ }^{13} \mathrm{C}$ NMR spectra were recorded on AVANCZ 500 spectrometers at $298 \mathrm{~K}$ by utilizing deuterated DMSO as solvent and tetramethylsilane (TMS) as standard. The compound was characterized by Flash EA 1112, CHNS-O elemental analysis instrument. The GC-mass spectra were measured by Finnigan TRACE MS. IR spectra were recorded on Perkin-Elmer spectrophotometer in the $4000-400 \mathrm{~cm}^{-1}$ region using a powered sample on a KBr plate. Fluorescence measurements were carried out with RF-5301PC. The melting points were determined using a Germany NETZSCH (DSC-204) instrument differential scanning calorimeter at $10{ }^{\circ} \mathrm{C} / \mathrm{min}$ with nitrogen flushing. 


\section{Synthesis and characterization of compounds 2,5-diphenyl-1,4-distyrylbenzene with}

two trans double bonds (trans-DPDSB)

2,5-diphenyl-1,4-distyrylbenzene was prepared by a 2-fold Wittig reaction from benzyltriphenyl-phosphonium bromide and [1,1';4',1"] terphenyl-2',5'-dicarbaldehyde at room temperature. The result compound was characterized as the cis-isomer (with two cis double bonds, cis-DPDSB) as following description. The phosphonium salt (200mg) and the dialdehyde (660mg) were added in a dry flask, which was wrapped with tinfoil, and the flask was flushed with nitrogen. Dry cooled THF (30mL) was added into the flask via injector and then Potassium tert-butoxide in dry THF was added slowly to allow the colored ylide formed to react with aldehyde groups between successive additions. When no color was observed upon addition of base, the mixture was stirred for another $12 \mathrm{~h}$ at room temperature. After the reaction was completed most of the solvent was moved under reduced pressure and then the concentrated solution was dropped into stirred methanol $(50 \mathrm{~mL}) .255 \mathrm{mg}$ of white product (yield: 87\%) was obtained by filtration. m.p. $192.5^{\circ} \mathrm{C} ;{ }^{1} \mathrm{H}$ NMR $(500 \mathrm{MHz}, \mathrm{DMSO}, \mathrm{ppm}) \delta$ 7.27-7.35 (m, 16H), $7.16(\mathrm{t}, 1.5 \mathrm{~Hz}, 4 \mathrm{H}), 7.14(\mathrm{~s}, 2 \mathrm{H}), 6.64(\mathrm{~d}, J=12 \mathrm{~Hz}, 2 \mathrm{H}) 6.42(\mathrm{~d}, J=$ $12 \mathrm{~Hz}, 2 \mathrm{H}) ;{ }^{13} \mathrm{C}$ NMR (500 MHz, DMSO, ppm) $\delta 140.51,140.04,137.52,135.17,132.13$, 131.45, 130.33, 129.62, 129.53, 129.20, 129.02, 128.18. FT-IR (KBr pellet, $\left.\mathrm{cm}^{-1}\right)$ 3076(w), 3056(m), 3014(m), 1599(w), 1493(w), 1475(m), 1444(m), 1408(w), 1385(w), 1074(m), 1026(m), 924(m), 908(m), 783(s), 764(s), 698(vs). MS: m/z: 434.2 (M). Anal. calcd. for C34H26: C, 93.97; H, 6.03; found C, 93.83; H, 6.17. 
<smiles>O=Cc1cc(-c2ccccc2)c(C=O)cc1-c1ccccc1</smiles>

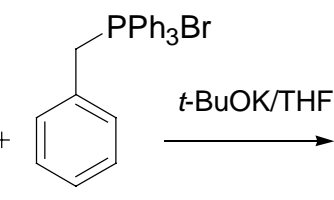<smiles>C(=C\c1cc(-c2ccccc2)c(/C=C\c2ccccc2)cc1-c1ccccc1)\c1ccccc1</smiles>

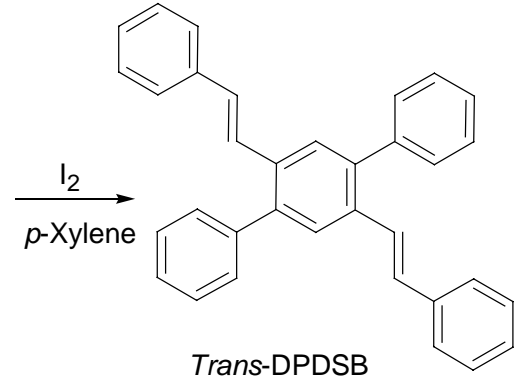

Trans-DPDSB

Scheme S1 Synthesis route of trans-DPDSB.

trans-DPDSB was prepared by refluxing the $p$-xylene solution of cis- isomer (200 $\mathrm{mg})$ for 12 $\mathrm{h}$ and in the solution little iodine was added as catalyzer. The result solution was concentrated using a rotatory evaporator and then dropped into stirred methanol $(20 \mathrm{~mL}) .190 \mathrm{mg}$ of yellow product was obtained by filtration (yield: 95\%). m.p. $251-254{ }^{\circ} \mathrm{C} ;{ }^{1} \mathrm{H}$ NMR (500 MHz, 25 ${ }^{\circ} \mathrm{C}$, DMSO, TMS, ppm): $\delta=7.81(\mathrm{~s}, 2 \mathrm{H}$; benzo H), $7.55(\mathrm{t}, J(\mathrm{HH})=7.36 \mathrm{~Hz}, 4 \mathrm{H}$; benzo $\mathrm{H})$, $7.50(\mathrm{~d}, J(\mathrm{HH})=7.22 \mathrm{~Hz}, 4 \mathrm{H}$; benzo H), $7.48(\mathrm{t}, J(\mathrm{HH})=7.21 \mathrm{~Hz}, 2 \mathrm{H}$; benzo H), $7.39(\mathrm{~d}, J$ $(\mathrm{HH})=7.33 \mathrm{~Hz}, 4 \mathrm{H}$; benzo $\mathrm{H}), 7.34(\mathrm{~d}, J(\mathrm{HH})=16.31 \mathrm{~Hz}, 2 \mathrm{H}$; olefinic $\mathrm{H}), 7.33(\mathrm{t}, J(\mathrm{HH})=$ $7.49 \mathrm{~Hz}, 4 \mathrm{H}$; benzo H), $7.24(\mathrm{t}, J(\mathrm{HH})=7.25 \mathrm{~Hz}, 2 \mathrm{H}$; benzo $\mathrm{H}), 7.08(\mathrm{~d}, J(\mathrm{HH})=16.35 \mathrm{~Hz}$, $2 \mathrm{H}$; olefinic H); ${ }^{13} \mathrm{C}$ NMR (500 MHz, $25{ }^{\circ} \mathrm{C}$, DMSO, TMS, ppm): $\delta=141.00,140.78,138.01$, 134.78, 130.64, 130.51, 129.64, 129.28, 128.60, 128.37, 128.15, 127.20, 126.89; FT-IR (KBr pellet, $\left.\mathrm{cm}^{-1}\right)$ 3053(m), 1595(m), 1493(m), 1477(m), 1446(m), 1396(w), 1340(w), 1072(m), 1024(m), 964(s), 922(w), 901(m), 877(vw), 852(w), 764(vs), 752(s), 704(vs); MS: m/z: 434.2 (M). Anal. calcd. for C34H26: C, 93.97; H, 6.03; found C, 93.85; H, 6.15. 


\section{Single crystal X-ray diffraction data of trans-DPDSB}

Single crystal of trans-DPDSB was prepared by vaporizing mix solvents of chloroform and methanol (1:2) slowly at room temperature under rigorous exclusion of light. The diffraction experiments were carried out on a Rigaku R-AXIS RAPID diffractometer equipped with a Mo-K $\alpha$ and Control Software using the RAPID AUTO at $293( \pm 2){ }^{\circ} \mathrm{C}$. Empirical absorption corrections were applied automatically. The structures were solved with direct methods and refined with a full-matrix least-squares technique using the SHELXS v. 5.1 programs, ${ }^{1}$ respectively. The space groups were determined from the systematic absences and their correctness was confined by successful solution and refinement of structures. Anisotropic thermal parameters were refined for all the non-hydrogen atoms. The hydrogen atoms were added in idealized position and refined with isotropic displacement. Crystal date refinement conditions and experimental details are tabulated in table S1.

Table S1 Crystallographic data and structure refinement for trans-DPDSB

\begin{tabular}{ll}
\hline \multicolumn{1}{l}{ Identification code } & trans-DPDSB \\
\hline Empirical formula & $\mathrm{C} 34 \mathrm{H} 26$ \\
Formula weight & 434.55 \\
Temperature & $293(2) \mathrm{K}$ \\
Wavelength & $0.71073 \AA$ \\
Crystal system, space group & Monoclinic, P2(1)/c
\end{tabular}


Unit cell dimensions

$$
\begin{aligned}
& \mathrm{a}=12.479(4) \AA \\
& \mathrm{b}=8.2482(2) \AA \\
& \mathrm{c}=24.018(8) \AA \\
& \text { alpha }=90 \mathrm{deg} . \\
& \text { beta }=91.2200(9) \mathrm{deg} . \\
& \text { gamma }=90 \mathrm{deg} .
\end{aligned}
$$

Volume

2471.7(8) $\AA^{3}$

Z, Calculated density

4, $1.168 \mathrm{Mg} / \mathrm{m}^{3}$

Absorption coefficient

$0.066 \mathrm{~mm}^{-1}$

$F(000)$

920

Crystal size

$0.309 \times 0.107 \times 0.062 \mathrm{~mm}$

Theta range for data collection

1.70 to $27.48 \mathrm{deg}$.

Limiting indices

$0<=\mathrm{h}<=16,0<=\mathrm{k}<=10,-31<=1<=31$

Reflections collected / unique

$5341 / 5341[\mathrm{R}(\mathrm{int})=0.0000]$

Completeness to theta $=27.48$

$94.1 \%$

Refinement method

Full-matrix least-squares on $\mathrm{F}^{2}$

Data / restraints / parameters

$5341 / 0 / 308$

Goodness-of-fit on $\mathrm{F}^{\wedge} 2$

0.979

Final $\mathrm{R}$ indices [I $>2 \operatorname{sigma}(\mathrm{I})]$

$\mathrm{R} 1=0.0496, \mathrm{wR} 2=0.0938$

$\mathrm{R}$ indices (all data)

$\mathrm{R} 1=0.2000, \mathrm{wR} 2=0.1507$ 
As shown in Figure S1, the thermal ellipsoids $C(27)$ and $C(28)$ are obviously bigger than other carbon atoms, which means the two atoms are instable because of their deviation from the conjugated plane of the backbone. But $\mathrm{C}(24)$ that acts as proton donor of aromatic $\mathrm{CH} / \pi$ hydrogen bond $\mathbf{I}$ is stabilized by the attracting force of this aromatic $\mathrm{CH} / \pi$ hydrogen bond. When the aromatic $\mathrm{CH} / \pi$ hydrogen bond $\mathbf{I I}$ is inspected, $\mathrm{C}(30 \mathrm{~A})$ that acts as proton donor is also stabilized.

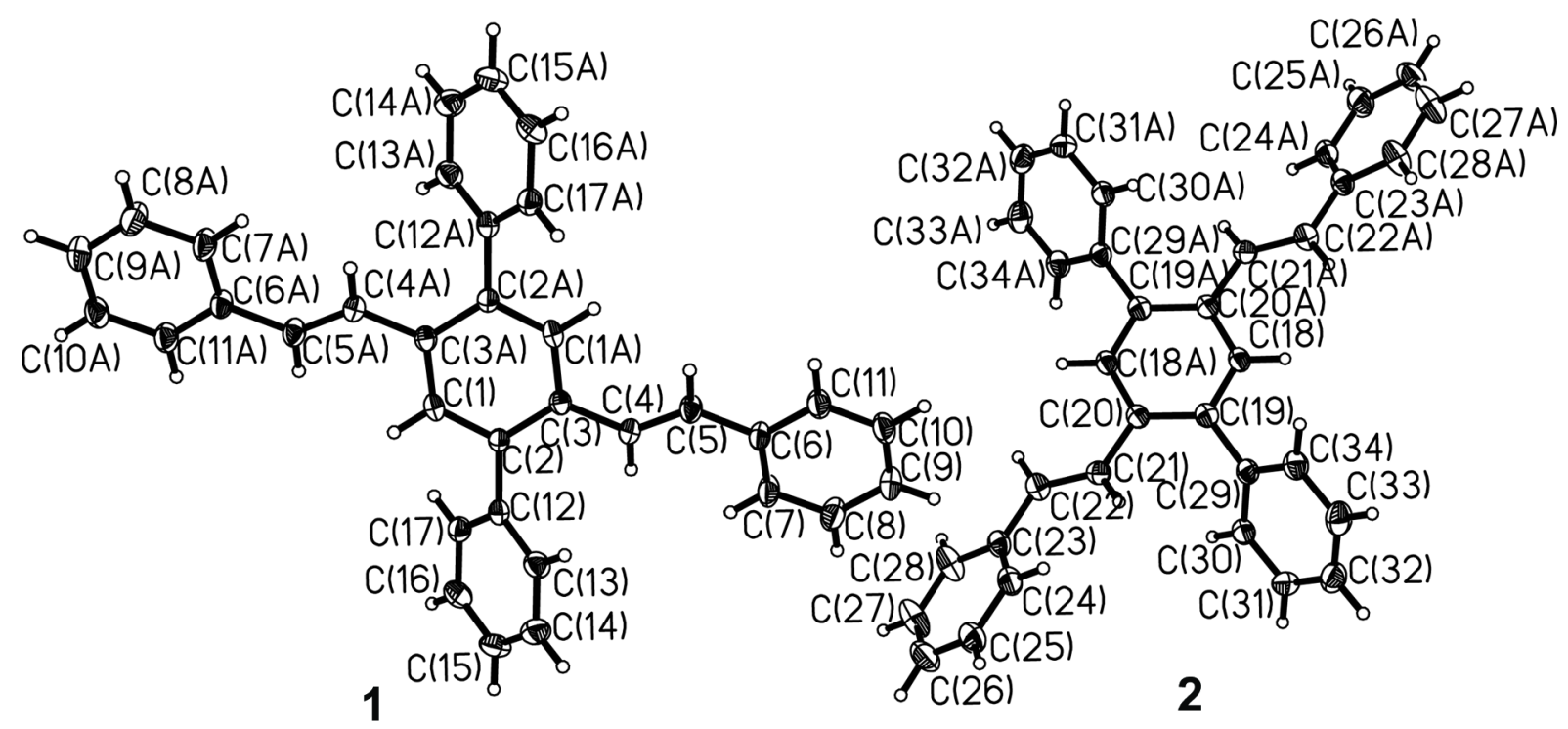

Figure S1 The molecular structures of trans-DPDSB in crystal. The backbone of conformation $\mathbf{1}$ is planar and that of conformation $\mathbf{2}$ is torsional. 


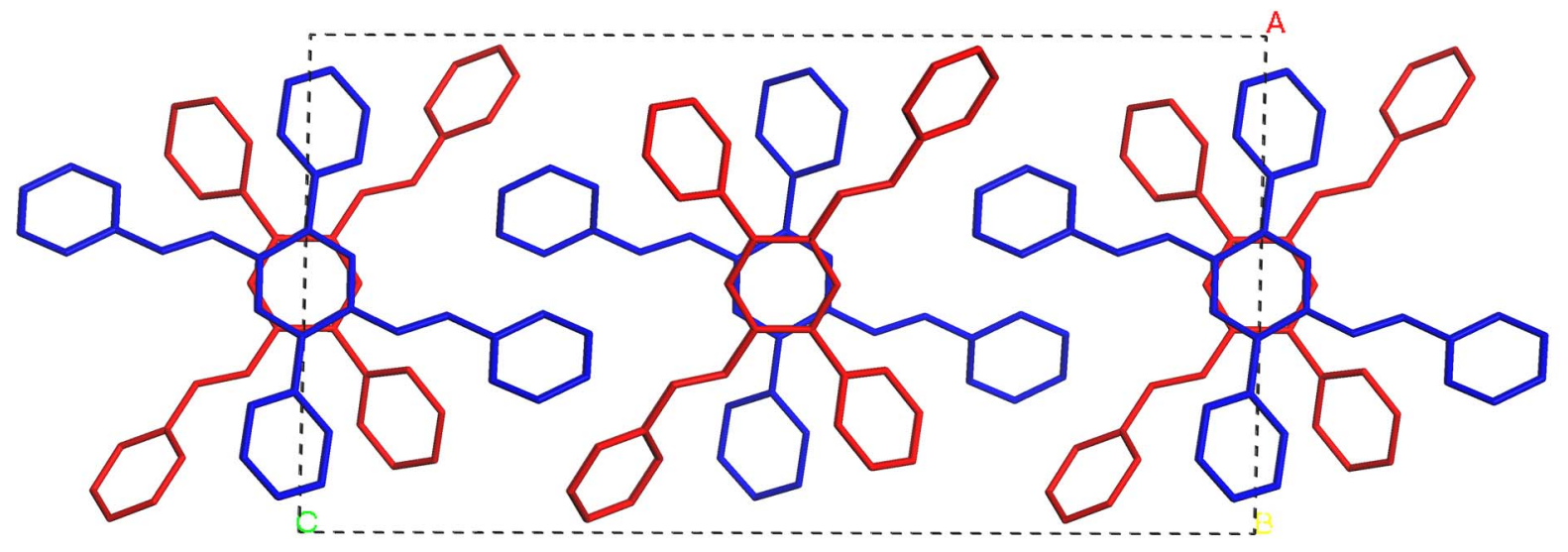

Figure S2 Packing image of trans-DPDSB in single crystal (viewed along $\mathbf{b}$ axis). Conformation $\mathbf{1}$ is drawn in blue and 2 in red. The hydrogen atoms have been omitted for clarity.

From Figure S2 we can see clearly that the molecules are packed into one-dimensional molecular columns along $\boldsymbol{b}$ axis, and they overlapped upon the center phenyl rings and one molecule is rotated relative to the other by an angle of $70^{\circ}$ about an axis that passes through the centers of both molecules. 


\section{Photoluminescence properties}

Figure S3 shows the PL spectra of trans-DPDSB (top) and trans-distyrylbenzene (trans-DSB, bottom) in dilute THF solution (square) and solid film (circle). From solution to film, the red shift for trans-DPDSB (cross stacking) is $10 \mathrm{~nm}$, while the red shift for trans-DSB (parallel stacking $^{2}$ ) is $60 \mathrm{~nm}$, which reveals that the intermolecular interactions of trans-DPDSB in solid state is much smaller than that of trans-DSB.

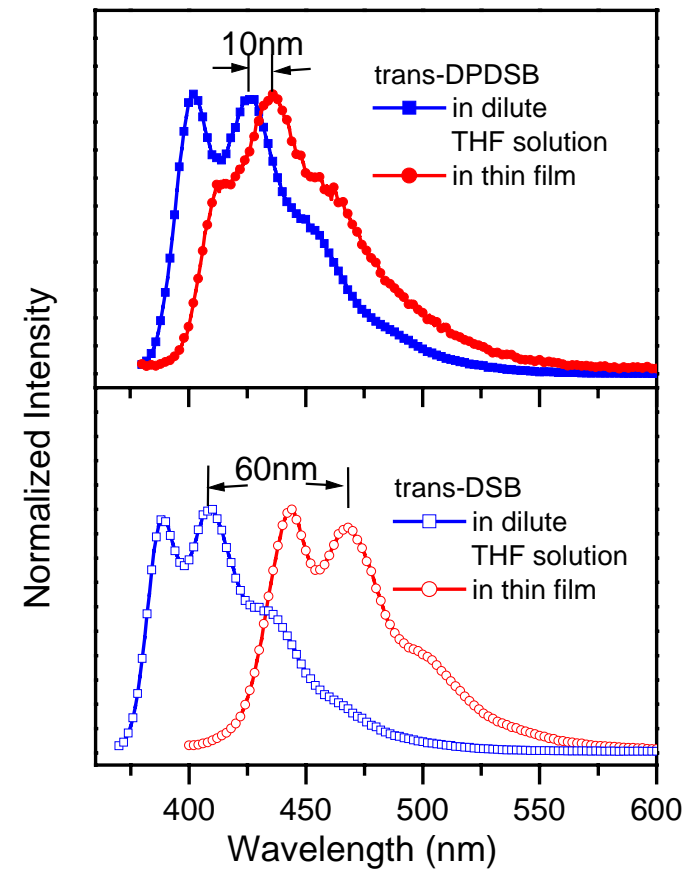

Figure S3 PL spectra of trans-DPDSB (top) and trans-DSB (bottom), in dilute THF solution (square) and solid film (circle). 


\section{Electroluminescence devices}

In order to investigate the carrier-transporting properties of trans-DPDSB, we fabricated two sets of OLEDs by vacuum deposition. These OLEDs have structures of ITO/NPB $(50 \mathrm{~nm}) /$ trans-DPDSB $(x \mathrm{~nm}) /$ rubrene $(0.1 \mathrm{~nm}) / \mathrm{Alq}(50-x \mathrm{~nm}) / \mathrm{LiF}(0.5 \mathrm{~nm}) / \mathrm{Al}$ for set 1 and ITO/NPB $(50 \mathrm{~nm}) /$ rubrene $(0.1 \mathrm{~nm}) /$ trans-DPDSB $(x \mathrm{~nm}) / \mathrm{Alq}(50-x \mathrm{~nm}) / \mathrm{LiF}(0.5 \mathrm{~nm}) / \mathrm{Al}$ for set 2. Here, $x$ varies from 5 to 20 for both sets of devices; indium tin oxide (ITO) is used as a transparent anode and $\mathrm{LiF} / \mathrm{Al}$ as a cathode; an ultrathin layer of 5,6,11,12,-tetraphenylnaphthacene (rubrene) serves as a carrier-trapping and yellow-emitting layer; ${ }^{3}$ NPB and Alq are used as hole- and electron-transporting layers, respectively. The organic films of NPB, trans-DPDSB, rubrene and Alq are sequentially deposited onto the ITO substrate at a pressure of around $3 \times 10^{-4} \mathrm{~Pa}$. The EL spectra and luminance are recorded on a PR650 spectrometer. Luminance - voltage and current-voltage characteristics are measured at room temperature. The emission area of the devices is $0.05 \mathrm{~cm}^{2}$, defined by the overlapping area of the anode and cathode. 


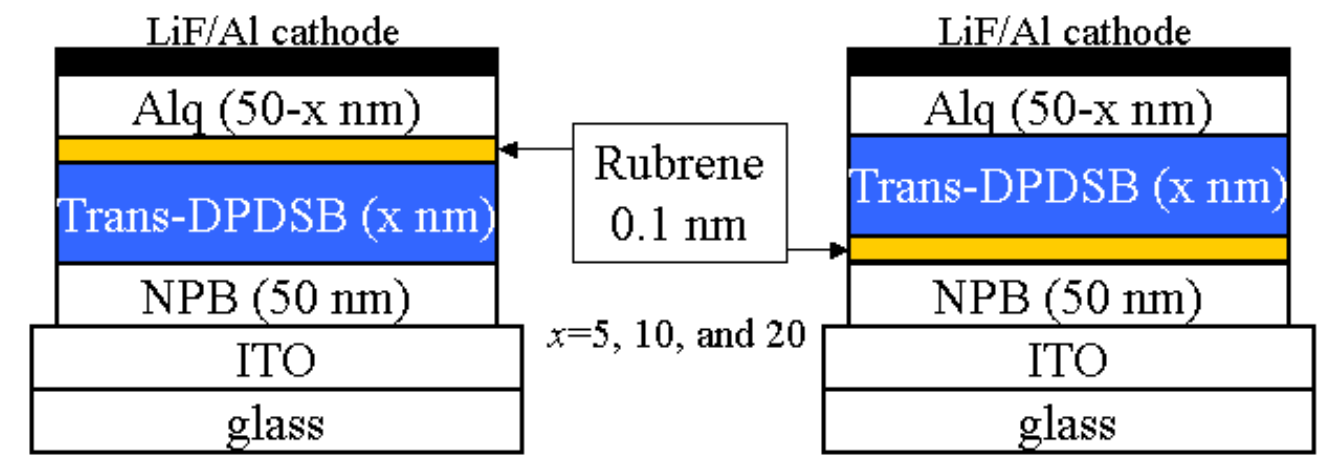

Device structure of A, B and C

Device structure of $D, E$ and $F$

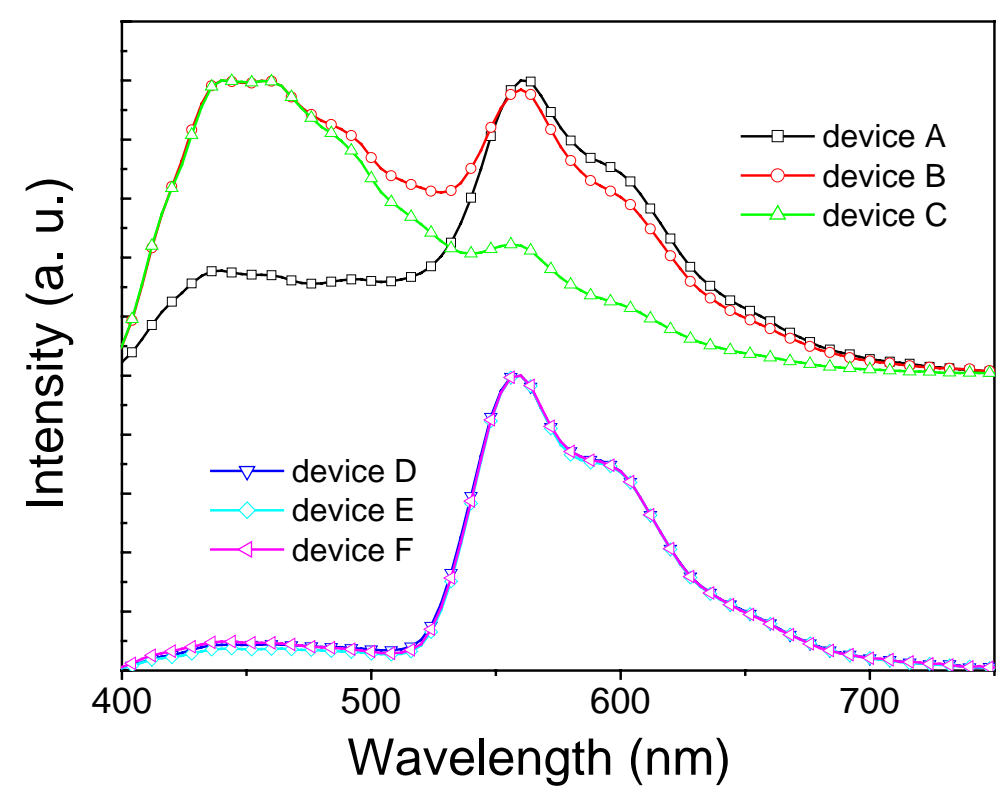

Figure S4 Normalized EL spectra of devices with structures of ITO/NPB (50 $\mathrm{nm}) /$ trans-DPDSB $(x \mathrm{~nm}) /$ rubrene $(0.1 \mathrm{~nm}) / \operatorname{Alq}(50-x \mathrm{~nm}) / \mathrm{LiF}(0.5 \mathrm{~nm}) / \mathrm{Al}$ (devices A, B, and C stand for $x=5,10$, and 20 , respectively) and ITO/NPB $(50 \mathrm{~nm}) /$ rubrene $(0.1$ $\mathrm{nm}) /$ trans-DPDSB $(x \mathrm{~nm}) / \mathrm{Alq}(50-x \mathrm{~nm}) / \mathrm{LiF}(0.5 \mathrm{~nm}) / \mathrm{Al}$ (devices D, E, F for $x=5,10$, and 20, respectively).

Normalized electroluminescent (EL) spectra of devices of sets 1 and 2 are shown in Figure S4, devices A, B, and C respectively denote OLEDs of set 1 with trans-DPDSB thickness of 5, 10, and $20 \mathrm{~nm}$; devices D, E, and F represent OLEDs of set 2 with trans-DPDSB thickness of 5, 
10, and $20 \mathrm{~nm}$, respectively. For devices of set 1, EL spectra significantly change from yellow (560 nm emission peak) to blue $(440 \mathrm{~nm})$ with the increasing thickness of trans-DPDSB. For devices of set 2, on the other hand, EL spectra remain almost unchanged with the changing thickness of trans-DPDSB. According to Figure S3 (top) and literature, ${ }^{3}$ the peaks at 440 and $560 \mathrm{~nm}$ can be attributed to the emission of trans-DPDSB and rubrene, respectively. It has been demonstrated that an ultrathin layer of rubrene can trap holes and then the cations of rubrene capture electrons to emit light. ${ }^{3}$ Consequently, the dependence of the EL spectra on the thickness of trans-DPDSB for devices of set 1 suggests a relative poor hole-transporting property for trans-DPDSB, which reduces the probability of holes that can transport though the trans-DPDSB layer and reach rubrene molecules with the increasing trans-DPDSB thickness. In the case of devices of set 2, emission from trans-DPDSB can hardly be seen in all devices, indicating that trans-DPDSB has a fairly good electron-transporting property, which results in the phenomenon that almost all electrons injected from the cathode reach rubrene molecules in spite of the thickness of trans-DPDSB.

In order to achieve the emission of trans-DPDSB in OLEDs, we fabricate a multilayer OLED according to the carrier-transporting properties with device structure of ITO/PEDOT:PSS/NPB(50 nm)/trans-DPDSB(20 nm)/Alq $(30 \mathrm{~nm}) / \mathrm{LiF}(0.5 \mathrm{~nm}) / \mathrm{Al}$ (device G), where PEDOT:PSS (poly(3,4-ethylenedioxythiophene): poly(styrene sulfonic acid)), NPB and Alq act as hole-injecting layer, hole-transporting layer and electron-transporting layer, respectively. The normalized EL spectrum is shown in Figure S5. Emission color of device G is in pure blue region with CIE coordinates of $(0.17,0.13)$. The achieved maximum 
luminescence and luminous efficiency are $2100 \mathrm{~cd} / \mathrm{m}^{2} @ 15 \mathrm{~V}$ and $1.53 \mathrm{~cd} \mathrm{~A}^{-1} @ 5 \mathrm{~V}$ respectively for this device.

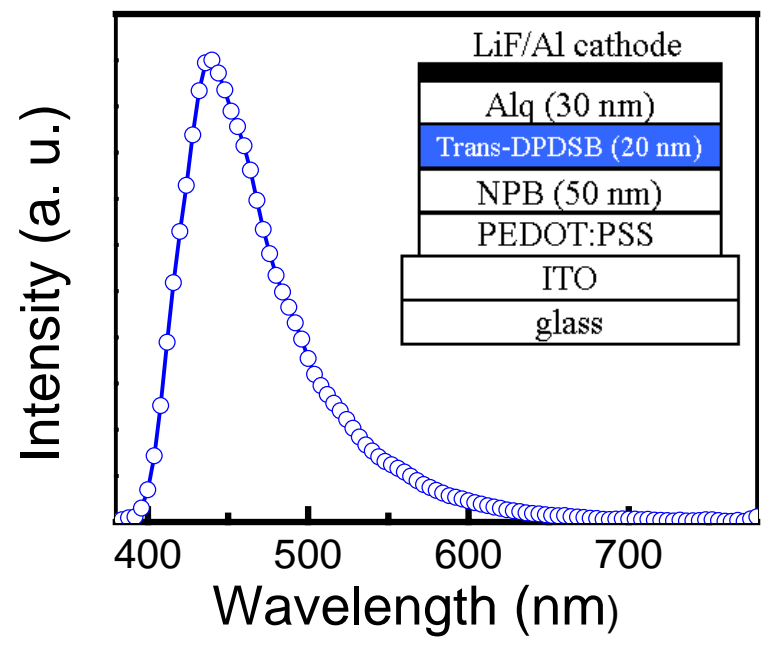

Figure S5 Normalized EL spectra of devices with structures of ITO/PEDOT:PSS/NPB(50 nm)/trans-DPDSB(20 nm)/Alq (30 nm)/LiF(0.5 nm)/Al. 


\section{Amplified spontaneous emission (ASE) of the needle-like crystal of trans-DPDSB}

The trans-DPDSB crystals are dispersed in water and this dispersion is dropped onto the quartz substrate and subsequently dried. So the crystals' face is in close contact with the substrate plane. The excitation source is the third harmonic $(355 \mathrm{~nm})$ of a Nd:YAG (yttrium-aluminum-garnet) laser with a repetition rate of $10 \mathrm{~Hz}$ and pulse duration of about 10ns. The intensity of the pump is adjusted using calibrated neutral density filters. The beam is focused using a cylindrical lens into a stripe whose shape is adjusted to $5 \mathrm{~mm} \times 1 \mathrm{~mm}$ by a slit. The emission is detected using a charge coupled device (CCD) spectrograph. Figure S6 shows the experimental configuration. All the measurements are carried out at room temperature under ambient conditions.

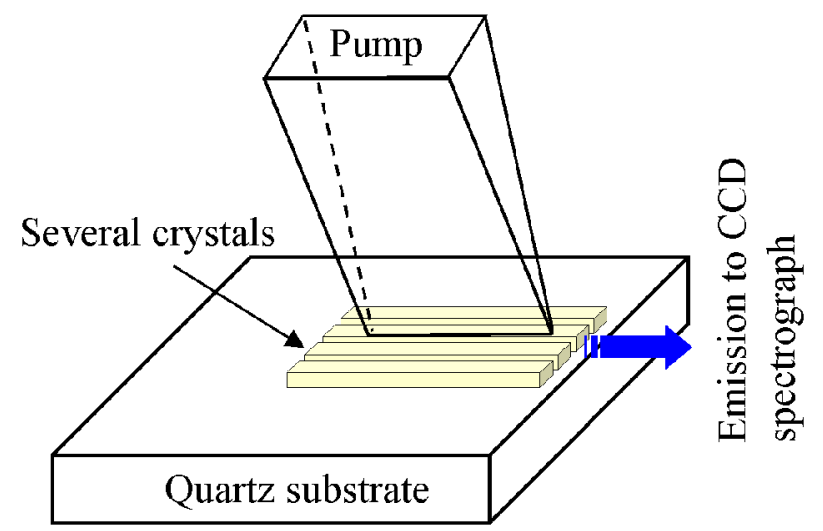

Figure S6 The experimental configuration.

Figure S7 shows the emission spectra of trans-DPDSB needlelike crystals as a function of the intensity of the incident laser. Under weak pump energy the emission spectra exhibit a broad feature with the peak at $441 \mathrm{~nm}$ and a shoulder at about $466 \mathrm{~nm}$. With the increase of pump energy, the spectra become narrow and the intensity of the shoulder become small compared to that of the peak at $441 \mathrm{~nm}$. The full widths at half maximum (FWHMs) change from $79 \mathrm{~nm}$ at $32 \mu \mathrm{J} /$ pulse to $14 \mathrm{~nm}$ at $1000 \mu \mathrm{J} /$ pulse. Because our samples are measured without 
protection of inert gas, further increasing the pump energy will damage the samples. However, we believe the FWHMs of the spectra will decrease further under higher pump energy.

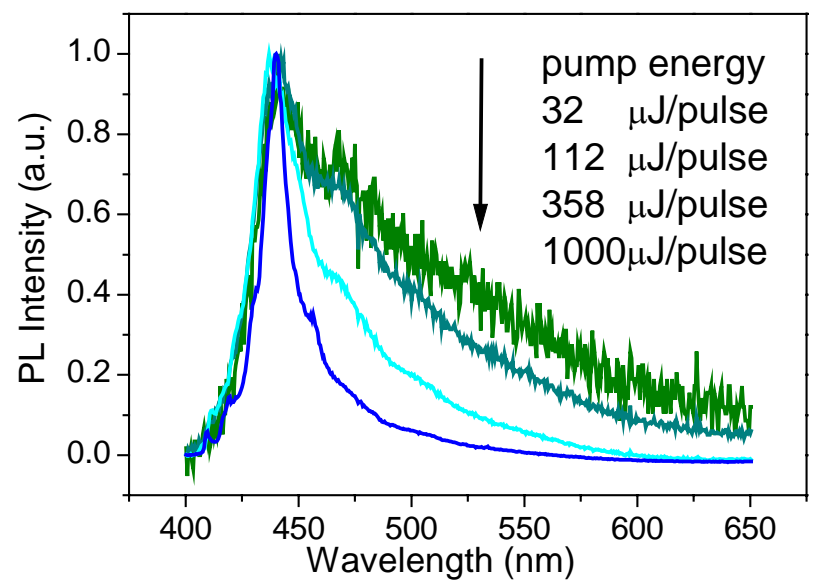

Figure S7 Changes from the initial broad blue emission amplified to the intense and narrow

blue band from fiber trans-DPDSB single crystals with increased pump energy.

Figure S8 shows the emission intensity integrated over all wavelengths (a) and FWHMs (b) as a function of the intensity of the incident laser. As can be seen, the relationship between the output intensity and the pump energy is not linear. The slope changes at $680 \mu \mathrm{J} /$ pulse, and the spectra narrowing occur at the same time. Based on the facts of self-waveguided emission and the nonlinear relationship between the output intensity and the pump laser intensity, the gain narrowing is attributed to the amplified spontaneous emission (ASE). Here the turning point of $680 \mu \mathrm{J} /$ pulse should be the threshold to get ASE from the trans-DPDSB needlelike crystals. If the needle tips can be cleaved to form two perfect cleavage planes at the ends of crystals, we believe that the blue lasing in organic trans-DPDSB crystals can be realized due to the resonant-cavity effect. 


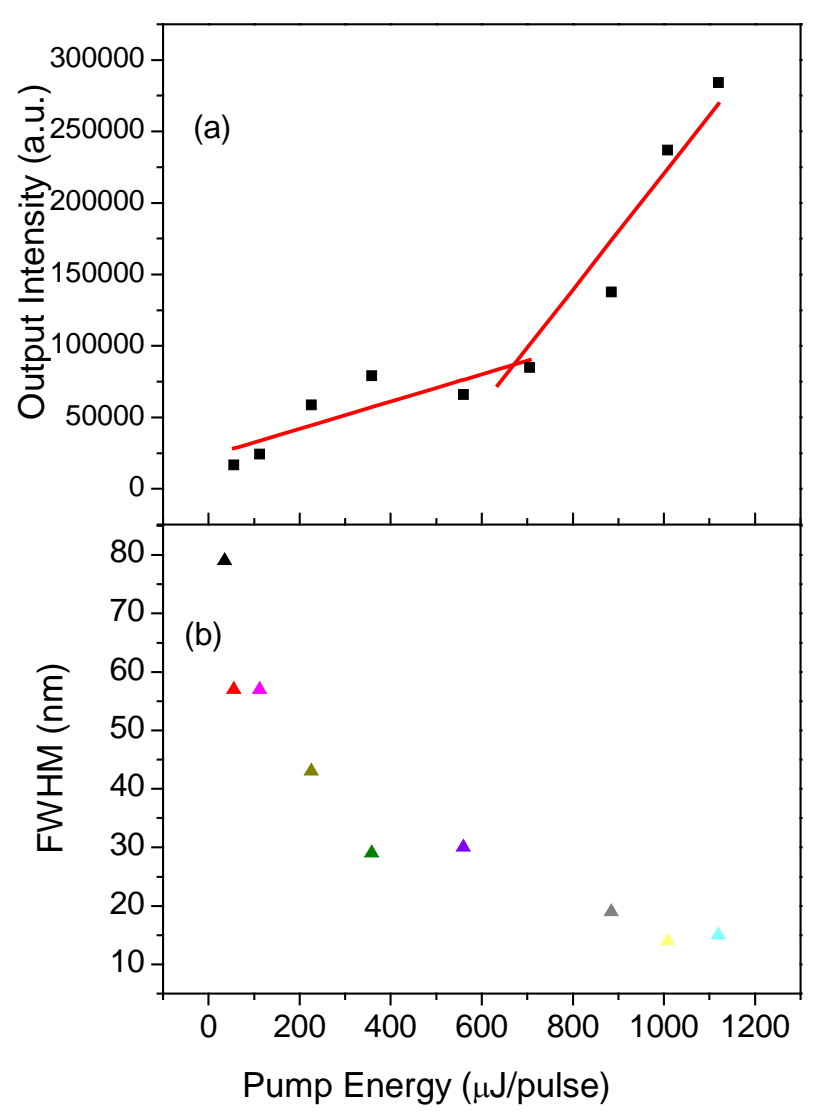

Figure S8 The emission intensity integrated over all wavelengths (a) and FWHMs (b) as a function of the intensity of the incident laser.

\section{Complete Ref. 27:}

Schneider, D.; Rabe, T.; Tiedl, T.; Dobbertin, T.; Kröger, M.; Becker, E.; Johannes, H. H.;

Kowalsky, W.; Weimann, T.; Wang, J.; Hinze, P.; Gerhard, A.; Stössel, P.; Vestweber, H. Adv.

Mater. 2005, 17, 31-34. 
Reference:

1. SHELXTL Reference Manual, version 5.1, Bruker AXS Inc., Madison, WI, 1998.

2. Wu, C. C.; DeLong, M. C.; Vardeny, Z. V.; Ferraris, J.P. Synth. Met. 2003, 137, 939-940.

3. Matsumura, M.; Furukawa, T. Jpn. J. Appl. Phys. 2001, 40, 3211-3213. 